\title{
Dynamic Co-Evolution Analysis of Low-Carbon Technology Innovation Compound System of New Energy Enterprise Based on the Perspective of Sustainable Development
}

\author{
Xu Yang \\ Harbin Engineering University \\ Yu Guo ( $\nabla$ gyu1991@hrbeu.edu.cn ) \\ Harbin Engineering University \\ Qiang Liu \\ Liaoning University of technology \\ Deming Zhang \\ Maintenance Branch of State Grid Anhui Electric Power Co.,Ltd
}

\section{Original article}

Keywords: new energy enterprise, low-carbon technology innovation compound system, dynamic coevolution, sustainable development

Posted Date: February 8th, 2021

DOI: https://doi.org/10.21203/rs.3.rs-159293/v1

License: (c) (i) This work is licensed under a Creative Commons Attribution 4.0 International License. Read Full License

Version of Record: A version of this preprint was published at Journal of Cleaner Production on March 1st, 2022. See the published version at https://doi.org/10.1016/j.jclepro.2022.131330. 


\section{Title Page}

Title: Dynamic Co-evolution Analysis of Low-carbon Technology Innovation Compound System of New Energy Enterprise Based on the Perspective of Sustainable Development

\section{Author Details:}

Xu Yang

${ }^{1}$ School of Economics and Management, Harbin Engineering University, Harbin 151000, China;

Email:yxu1969@163.com

Yu Guo *(Corresponding Author)

${ }^{1}$ School of Economics and Management, Harbin Engineering University, Harbin 151000, China;

Email:gyu1991@hrbeu.edu.cn

Qiang Liu

${ }^{2}$ School of Economics and Management, Liaoning University of Technology, Jinzhou, 111,China;

Email: xiaoqiang1986625@163.com

Deming Zhang

${ }^{3}$ Maintenance Branch of State Grid Anhui Electric Power Co., Ltd, Hefei,222, China;

Email: MING20200666@163.com 


\title{
Dynamic Co-evolution Analysis of Low-carbon Technology Innovation Compound System of New Energy Enterprise Based on the Perspective of Sustainable Development
}

\begin{abstract}
Background: The implementation of low-carbon economy is the key to sustainable economy and society development, and low-carbon technological innovation of new energy enterprise is the core driving force based on the perspective of sustainable development.

Method: This study establishes the low-carbon technology innovation compound systems and evaluation index order systems of new energy enterprise, integrates synergy theory and genetic algorithms, and constructs the dynamic co-evolution model of low-carbon technology innovation compound systems of new energy enterprise, expounds the order and stability of the compound systems.
\end{abstract}

Results: Based on the statistical data of 12 representative enterprises in "top 30 new energy enterprises" from 2010 to 2019, this paper establishes and analyzes the corresponding coevolution model. It is found that the gap of low-carbon technology innovation level between different new energy enterprises is narrowing. Among them, the level of new energy comprehensive enterprises is slightly higher than that of other types of enterprises, and that of central enterprises is slightly higher than that of private enterprises.

Conclusion: The results consistently show that the model can better reflect the dynamic co-evolution relationships of low-carbon technology innovation compound systems of new energy enterprise, and reveal the partial competitive substitution, partial competitive coexistence and completeness among the three subsystems of input, output and support in the compound systems in detail. The three situations of independent coexistence fully demonstrate the competition and cooperation relationships among subsystems and the stability of overall compound systems, which provide new research direction for low-carbon technology innovation research for new energy enterprise.

Key words: new energy enterprise; low-carbon technology innovation compound system; dynamic co-evolution; sustainable development

\section{Introduction}

With the global response to climate change on a large scale, low-carbon economy, as a low-emission, low-energy, and low-polluting economic development mode, has become the fundamental way to resolve the contradictions between population, resources and environmental systems in the development of human society, and which has gradually become the common 
choice for sustainable development of all countries in the world[1-5]. Scholars have actively discussed about the low-carbon technology innovation systems, which can be summarized as the following two points: one is the research focusing on the specific levels and latitudes of low-carbon technology innovation systems (including the connotation, constituent elements, functions, structure and operation mechanism, etc.)[6-10]; the other is the low-carbon technology innovation systems that emphasize on the research of industrial dimensions (which can be subdivided into low-carbon industrial technology innovation systems and cross-industry low-carbon technology innovation systems)[11-14], the geographical dimensions of low-carbon technology innovation systems (which can be subdivided into the regional low-carbon technology innovation systems, the national low-carbon technology innovation systems and the transnational economic regional low-carbon technology innovation systems)[15-18].

With the substantial increase in energy consumption and the gradual depletion of traditional energy sources, the sustainable development of national economy will inevitably require the development and utilization of new energy sources. The sustainable development theory emphasizes on the social and ecological nature of enterprise, the harmony and continuity of economic, social, and ecological benefits. New energy sources have the characteristics of no-emitting pollutants and relatively safe applications, and they have more potential for development. Faced with the requirements of sustainable development and low-carbon economic development, new energy enterprises have been given the important mission, and a large number of theoretical and empirical studies have proved that low-carbon technological innovation of new energy enterprises is the core of their development[11, 14, 17]. The low-carbon technology innovation of new energy enterprise refers to a systematic process. Therefore, a more systematic analysis tool is needed to analyze the low-carbon technology innovation of new energy enterprises $[16,18]$. The compound systems are an open and complex dynamic large systems with specific structure and function formed by interweaving, interaction and mutual penetration of subsystems with different attributes. Compared with general systems, compound systems have the following characteristics: (1)Differences. The attributes of internal subsystems of the compound systems are different due to the integration and complementarity of certain functions. (2)Self-organization and organizational characteristics. The compound systems have the characteristics of both natural and artificial systems. (3)Coherence. The various subsystems in the compound systems are coupled into the new overall effect through interaction. (4) Dynamic. The complexity and overall function of the compound systems will change with time[19, 20]. This study combines with low-carbon technology innovation systems, compound systems and other theories based on the perspective of sustainable development, and further analyzes the dynamic 
co-evolution of low-carbon technology innovation compound systems based on the development of new energy enterprises.

Sustainable development is the development that can not only meet the needs of contemporary people, but also does not harm the ability of future generations to meet their needs. It is the most rational choice made by mankind to balance the coordination development of economy, environment and society. The comprehensive sustainable development of new energy enterprises, and low-carbon technology innovation will become an important part[21-23]. Based on the perspective of sustainable development, it is essential to start from the inherent laws of energy conservation, emission reduction, and low-carbon economic development in order to construct the low-carbon technology innovation compound systems for new energy enterprises. Low-carbon technology innovation compound systems of new energy enterprises refer to that the new energy enterprises enhance low-carbon economic benefits and achieve sustainable growth goals, give full play to the initiative of low-carbon technology innovation, efficiently allocate corporate innovation resources, and extensively carry out low-carbon technology innovation. The systems enable enterprises to apply, diffuse and promote low-carbon innovation products, new processes and new services[24]. According to the process view of technology innovation and research foundation of a large number of scholars[25-29], the low-carbon technology innovation compound systems of new energy enterprises includes three subsystems of low-carbon technology innovation input systems (hereinafter referred to as "input systems"), low-carbon technology innovation output systems (Hereinafter referred to as the "output systems") and the low-carbon technology innovation support systems (hereinafter referred to as the "support systems"), each of which has its own unique role, the three subsystems relate to each other and restrict with each other.

First of all, the supply of resources (funds, technology, manpower) of the input systems provide basic support for the output system development [18]. Reasonable and sufficient input can strengthen the research on low-carbon technology innovation and overcome the disadvantages of low-carbon technology innovation. The output systems utilize the resources provided by the input systems for the application, diffusion and promotion of innovative results, adjust the input intensity, optimize the input structure, and regulate the input behavior based on the feedback of innovation technology, so that the input systems efficiently allocate the low-carbon technology innovation resources of new energy enterprises [30, 31]. Secondly, the investment systems provide necessary material resources and cooperation opportunities for the stability and development of the support systems, guarantee its support strength, expand its support range, and give full play to its software and hardware dual support. At the same time, a good support systems can better guide 
the inflow, absorption and digestion of various resources invested in the systems, and solve the problem of uneven distribution of resources of new energy enterprises. Finally, the output systems are concrete representations of actual value of the support systems, reflecting the role of external society, economy, and culture on low-carbon technology innovation [32-35]. Correspondingly, the support systems provide the infrastructures (financial environment, cultural environment and market environment, etc.) that the output systems depend on, ensure the efficiency of popularization and application of low-carbon technology innovation in the output systems, provide financing channels, provide diversified and reasonable ways for the transformation of low-carbon technology innovation achievements, reduce the risk of transformation of low-carbon technology innovation achievements, and expand the economic scale of the output systems [35, 36]. On the other hand, too much or too little resource inputs in the input system will lead to resource redundancy or insufficient in the transformation of low-carbon technology innovation achievements, which are not conducive to the output systems to obtain the broader market space and cannot realize its feedback to the input systems [32]. In addition, unreasonable resource inputs into the systems are likely to squeeze or exclude the low-carbon technology innovation cooperation that supports the systems, worsen the low-carbon technology innovation environment, and affect resource input and resource allocation. The input systems, output systems, and support systems are all opposed and unified, they are under the circumstances of competition and cooperation relationships. The synergy among them is the internal driving force for low-carbon technology innovation of new energy enterprise, can make full use of their mutual promotion, reduce mutual obstacles, coordinate the development of compound systems composed of "input-output-support", which has great guiding significance for the low-carbon technology innovation of new energy enterprise.

\section{Basic theory of synergetics and order model}

\subsection{Basic principles of synergetics}

Synergetics reveal the general laws of complex large-scale systems. It is believed that complex large-scale systems are composed of many distinct subsystems, structures, elements, etc. However, from the perspective of the overall systems, these unbalanced subsystems will pass through the nonlinearity among their elements. The role produces the certain synergy and competition, and guides the systems to transform from disorder to order. Therefore, the core content of synergetics includes: order parameters, synergy and domination, synergy and competition, and fluctuation effects[37, 38]. Order parameters derive from the coordination and cooperation among subsystems, and at the same time they play a role in dominating their behavior, which can guide the generation of new elements and form an orderly system structure. Many order 
parameters compete with each other to win and dominate the behavior of the entire systems. The winning order parameters can serve the individual parts of the systems, make them cooperate and help each other, dominate the evolution of the systems and promote the continuous leap of the systems[39]. Under the vision of synergetics theory, seeking the structures of various systems can form a common general law followed by self-organization, organization and integration. The co-evolution process of the compound systems refers to the exchange of matter, energy and information among the compound systems and the environment. After the evolutionary process of birth, growth, maturity, decline, and death, a certain level of development is finally formed. Their evolutionary trajectories belong to the S-shaped curve, and the classic logistic growth model is usually used to describe the co-evolution process of the compound system, as in formula (1).

$$
\frac{d X}{d t}=\alpha X(1-X)
$$

Among them, $\mathrm{X}$ is the order parameter of the compound system, which is the multiplication coefficient of the compound system, and $\mathrm{X}$ on the right side of the equation is the dynamic factor, and $(1-\mathrm{X})$ is the deceleration factor.

\subsection{Order degree of compound systems analysis}

Let variable $u_{i}(i=1,2,3)$ be the order parameters of input systems $S_{1}$, output system $S_{2}$ and support system $S_{3}, u_{i j}$ is the $j$ index of the $i$ order parameter, $X_{i j}(j=1,2, \cdots, n)$ means its value, $\alpha_{i j}$ and $\beta_{i j}$ are the upper limit and lower limit of the sequence parameter of systems respectively, we can obtain the orderly contribution parameters of the three subsystems to the compound system $u_{i j}$, it can be calculated by formula (2):

$$
u_{i j}= \begin{cases}\left(X_{i j}-\beta_{i j}\right) /\left(\alpha_{i j}-\beta_{i j}\right) & X_{i j} \text { and } u_{i j} \text { are benefitindexes } \\ \left(\alpha_{i j}-X_{i j}\right) /\left(\alpha_{i j}-\beta_{i j}\right) & X_{i j} \text { and } u_{i j} \text { are cost indexes }\end{cases}
$$

In formula (2), $u_{i j}$ is the contribution degree of the variable to subsystems $S_{i}$, which reflects the satisfaction degree of each index reaching the target, so the value range is $0 \leq u_{i j} \leq 1$. Considering the interaction and mutual influence of the three subsystems in the low-carbon technology innovation system of new energy enterprises, we generally adopt the geometric average method and linear weighted sum method to calculate the total contribution to the order degree of each order parameter in the subsystems [40].

$$
u_{i}=\sum_{j=1}^{m} \lambda_{i j} u_{i j}, \sum_{j=1}^{m} \lambda_{i j}=1
$$

In formula (3), $u_{i}$ is the contribution of the subsystems to the order of the total systems, $\lambda_{i j}$ is the weight of each order parameter, this study uses the CRITIC method to determine the weights.

Each order parameter has a different degree of contribution to the subsystems, and its index 
weight is also different. The CRITIC method comprehensively measures the objective weights of indicators based on the contrast strength of evaluation indicators and the conflicts among indicators. It considers the variance of indicators while taking the correlations among indicators into account. It does not rely on numerical values to judge importance, but uses data to carry out the calculation and empirical analysis. Scientific evaluation of its own objective attributes is a better objective weighting method than entropy method and standard deviation method[41]. The contrast strength of the CRITIC method refers to the sizes of the value gaps among the evaluation schemes of the same indicator, which is reflected by the standard deviation. The larger the value is, the greater the fluctuation is, indicating that the greater the value gaps among the various schemes are, the higher the weight is. The conflicts among the indicators are based on the correlations among the indicators, and the correlation coefficient is used to reflect the strong positive correlations among the two indicators, indicating that the conflicts between the two are small, the information reflected is more similar, the weight will be lower[41].

Given $m$ sample to be evaluated, $n$ evaluation indicators, let $C_{j}$ be the total amount of information contained in the $j$ indicator. $C_{j}=S_{j} \sum_{i=1}^{n}\left(1-R_{i j}\right)(j=1,2 \cdots, n)$, among them, $S_{j}$ is the standard deviation, $S_{j}=\sqrt{\frac{\sum_{i=1}^{m}\left(x_{i j}-\bar{x}_{j}\right)^{2}}{m-1}}, \quad \bar{x}_{j}=\frac{1}{m} \sum_{i=1}^{m} x_{i j} \cdot R_{j}=\sum_{i=1}^{m}\left(1-r_{i j}\right), r_{i j}$ is the correlation coefficient between evaluation index $i$ and $j$.

The greater $C_{j}$ is, the greater the amount of information contained in the $j$ evaluation index is, and the greater its importance is, therefore, the objective weight of the $j$ evaluation index is as follows:

$$
W_{j}=\frac{C_{j}}{\sum_{j=}^{n} C_{j}}
$$

\section{Co-evolution model of low-carbon technology innovation compound systems of new energy enterprises}

\subsection{Co-evolution model construction of low-carbon technology innovation compound systems of new energy enterprises}

Given the input systems $S_{1}$, output systems $S_{2}$ and support systems $S_{3}$. In order to further illustrate the competitive effects of these three systems in the evolution process, the parameter $\beta_{i j}(i, j=1,2,3)$ is used to represent for the competitive influence of systems $j$ on systems 
$i$. In summary, the co-evolution model of low-carbon technology innovation compound systems of new energy enterprises is as follows:

$$
\left\{\begin{array}{l}
\frac{d X_{1}}{d t}=f_{1}\left(X_{1}, X_{2}, X_{3}\right)=Y_{1}=\alpha_{1} X_{1}\left(1-X_{1}-\beta_{12} X_{2}-\beta_{13} X_{3}\right) \\
\frac{d X_{2}}{d t}=f_{2}\left(X_{1}, X_{2}, X_{3}\right)=Y_{2}=\alpha_{2} X_{2}\left(1-X_{2}-\beta_{21} X_{1}-\beta_{23} X_{3}\right) \\
\frac{d X_{3}}{d t}=f_{3}\left(X_{1}, X_{2}, X_{3}\right)=Y_{3}=\alpha_{3} X_{3}\left(1-X_{3}-\beta_{31} X_{1}-\beta_{32} X_{2}\right)
\end{array}\right.
$$

Among them, $X_{1}, X_{2}, X_{3}$ are the order development level of $S_{1}, S_{2}, S_{3}$ respectively, $\alpha_{1}, \alpha_{2}$, and $\alpha_{3}$ are value-added coefficients, which indicate the degree of development of the three subsystems in the low-carbon technology innovation compound systems of new energy enterprises.

$\alpha_{i}>0(i, j=1,2,3)$ indicates that the systems themselves are in an evolutionary state as a whole, $\alpha_{i}<0(i, j=1,2,3)$ indicates that the systems themselves are in a degraded state as a whole. $\beta_{i j}>0(i, j=1,2,3)$ indicates that there are competitive relationships between systems $j$ and systems $i$, the evolution of systems $j$ themselves limits the development of systems $i$ to varying degrees. $\beta_{i j}<0(i, j=1,2,3)$ shows that there are cooperative relationships between systems $j$ and systems $i$, the evolution of systems $j$ is conducive to the development of systems $i$, and it is a synergy that promotes each other.

Specifically, the parameters $\beta_{12}, \beta_{13}$ in the evolution equation (5) respectively reflect the influence of the output systems and the support systems on the input systems. The state changes of the output systems and the support systems will affect the order level of the input systems. The parameters $\beta_{21}, \beta_{23}$ reflect the influence of the input systems and the support systems on the output systems respectively. The state changes of the input systems and the support systems will affect the order level of the output systems. Parameters $\beta_{31}, \beta_{32}$ reflect the impact of the input systems and the output systems on the support systems respectively. Changes in the state of the input systems and output systems will affect the order level of the support systems.

\subsection{Co-evolution model analysis of low-carbon technology innovation compound systems of new energy enterprises}

(1) The stable point of the evolution equation

Let $f_{1}\left(X_{1}, X_{2}, X_{3}\right)=0, f_{2}\left(X_{1}, X_{2}, X_{3}\right)=0, f_{3}\left(X_{1}, X_{2}, X_{3}\right)=0$, and get five balance points: $Q_{1}(0,0,0), Q_{2}(0,0,1), Q_{3}(0,1,0), Q_{4}(1,0,0), Q_{5}\left(\frac{A_{1}}{A}, \frac{A_{2}}{A}, \frac{A_{3}}{A}\right)$, among them:

$A=\left|\begin{array}{ccc}1 & \beta_{12} & \beta_{13} \\ \beta_{21} & 1 & \beta_{23} \\ \beta_{31} & \beta_{32} & 1\end{array}\right|, A_{1}=\left|\begin{array}{ccc}1 & \beta_{12} & \beta_{13} \\ 1 & 1 & \beta_{23} \\ 1 & \beta_{32} & 1\end{array}\right|, A_{2}=\left|\begin{array}{ccc}1 & 1 & \beta_{13} \\ \beta_{21} & 1 & \beta_{23} \\ \beta_{31} & 1 & 1\end{array}\right|, A_{3}=\left|\begin{array}{ccc}1 & \beta_{12} & 1 \\ \beta_{21} & 1 & 1 \\ \beta_{31} & \beta_{32} & 1\end{array}\right|$ 
Then the coordinates of point $Q_{5}$ are:

$$
\begin{aligned}
& X_{10}=\frac{1-\beta_{23} \beta_{32}+\beta_{12} \beta_{23}-\beta_{12}+\beta_{13} \beta_{32}-\beta_{13}}{1+\beta_{12} \beta_{23} \beta_{31}+\beta_{13} \beta_{21} \beta_{32}-\beta_{23} \beta_{33}-\beta_{12} \beta_{21}-\beta_{13} \beta_{31}} \\
& X_{20}=\frac{1-\beta_{23}+\beta_{23} \beta_{31}-\beta_{21}+\beta_{13} \beta_{21}-\beta_{13} \beta_{31}}{1+\beta_{12} \beta_{23} \beta_{31}+\beta_{13} \beta_{21} \beta_{32}-\beta_{23} \beta_{33}-\beta_{12} \beta_{21}-\beta_{13} \beta_{31}} \\
& X_{30}=\frac{1-\beta_{32}+\beta_{31} \beta_{12}-\beta_{12} \beta_{21}+\beta_{21} \beta_{32}-\beta_{31}}{1+\beta_{12} \beta_{23} \beta_{31}+\beta_{13} \beta_{21} \beta_{32}-\beta_{23} \beta_{33}-\beta_{12} \beta_{21}-\beta_{13} \beta_{31}}
\end{aligned}
$$

The criterion for judging whether the equilibrium point $\left(X_{10}, X_{20}, X_{30}\right)$ of the differential equation is stable is as follows:

$$
\begin{gathered}
p=\frac{\partial f_{1}\left(X_{10}, X_{20}, X_{30}\right)}{\partial X_{10}}+\frac{\partial f_{2}\left(X_{10}, X_{20}, X_{30}\right)}{\partial X_{20}}+\frac{\partial f_{3}\left(X_{10}, X_{20}, X_{30}\right)}{\partial X_{30}} \\
q=\left|\begin{array}{ll}
\frac{\partial f_{1}\left(X_{10}, X_{20}, X_{30}\right)}{\partial X_{10}} \frac{\partial f_{1}\left(X_{10}, X_{20}, X_{30}\right)}{\partial X_{20}} \frac{\partial f_{1}\left(X_{10}, X_{20}, X_{30}\right)}{\partial X_{30}} \\
\frac{\partial f_{2}\left(X_{10}, X_{20}, X_{30}\right)}{\partial X_{10}} \frac{\partial f_{2}\left(X_{10}, X_{20}, X_{30}\right)}{\partial X_{20}} \frac{\partial f_{2}\left(X_{10}, X_{20}, X_{30}\right)}{\partial X_{30}} \mid \\
\frac{\partial f_{3}\left(X_{10}, X_{20}, X_{30}\right)}{\partial X_{10}} \frac{\partial f_{3}\left(X_{10}, X_{20}, X_{30}\right)}{\partial X_{20}} \frac{\partial f_{3}\left(X_{10}, X_{20}, X_{30}\right)}{\partial X_{30}} \mid
\end{array}\right|-\frac{\partial f_{1}\left(X_{10}, X_{20}, X_{30}\right)}{\partial X_{10}} \cdot \frac{\partial f_{2}\left(X_{10}, X_{20}, X_{30}\right)}{\partial X_{20}}-\frac{\partial f_{1}\left(X_{10}, X_{20}, X_{30}\right)}{\partial X_{10}} \cdot \frac{\partial f_{3}\left(X_{10}, X_{20}, X_{30}\right)}{\partial X_{30}} \\
-\frac{\partial f_{2}\left(X_{10}, X_{20}, X_{30}\right)}{\partial X_{20}} \cdot \frac{\partial f_{1}\left(X_{10}, X_{20}, X_{30}\right)}{\partial X_{10}}-\frac{\partial f_{2}\left(X_{10}, X_{20}, X_{30}\right)}{\partial X_{30}} \cdot \frac{\partial f_{3}\left(X_{10}, X_{20}, X_{30}\right)}{\partial X_{20}} \\
+\frac{\partial f_{1}\left(X_{10}, X_{20}, X_{30}\right)}{\partial X_{20}} \cdot \frac{\partial f_{2}\left(X_{10}, X_{20}, X_{30}\right)}{\partial X_{10}}+\frac{\partial f_{1}\left(X_{10}, X_{20}, X_{30}\right)}{\partial X_{30}} \cdot \frac{\partial f_{3}\left(X_{10}, X_{20}, X_{30}\right)}{\partial X_{10}}
\end{gathered}
$$

When $p<0, q<0, r<0$, balance point $\left(X_{10}, X_{20}, X_{30}\right)$ is stable; When $p \geq 0$, balance point $\left(X_{10}, X_{20}, X_{30}\right)$ is unstable, among them,

$$
\begin{aligned}
& \frac{\partial f_{1}}{\partial X_{1}}=\alpha_{1}\left(1-2 X_{1}-\beta_{12} X_{2}-\beta_{13} X_{3}\right), \frac{\partial f_{1}}{\partial X_{2}}=-\alpha_{1} \beta_{12} X_{1}, \frac{\partial f_{1}}{\partial X_{3}}=-\alpha_{1} \beta_{13} X_{1} \\
& \frac{\partial f_{2}}{\partial X_{2}}=\alpha_{2}\left(1-2 X_{2}-\beta_{21} X_{1}-\beta_{23} X_{3}\right), \frac{\partial f_{2}}{\partial X_{1}}=-\alpha_{2} \beta_{21} X_{2}, \frac{\partial f_{2}}{\partial X_{3}}=-\alpha_{2} \beta_{23} X_{2} \\
& \frac{\partial f_{3}}{\partial X_{3}}=\alpha_{3}\left(1-2 X_{3}-\beta_{31} X_{1}-\beta_{32} X_{2}\right), \frac{\partial f_{3}}{\partial X_{1}}=-\alpha_{3} \beta_{31} X_{3} \frac{\partial f_{3}}{\partial X_{2}}=-\alpha_{3} \beta_{32} X_{3}
\end{aligned}
$$

The calculation formula for judging the stability of the equilibrium points are shown in Table 1.

Table 1 The calculation formula for judging the stability of the equilibrium points

\begin{tabular}{cccc} 
Balance Point & $p$ & $q$ & $r$ \\
\hline$Q_{1}(0,0,0)$ & $\alpha_{1}+\alpha_{2}+\alpha_{3}$ & $\alpha_{1} \alpha_{2} \alpha_{3}$ & $-\alpha_{1} \alpha_{2}+\alpha_{1} \alpha_{3}+\alpha_{2} \alpha_{3}$ \\
$Q_{2}(0,0,1)$ & $\left(\alpha_{1}+\alpha_{2}+\alpha_{3}\right)-\left(2 \alpha_{3}+\alpha_{1} \beta_{13}+\alpha_{2} \beta_{23}\right)-\alpha_{1} \alpha_{2} \alpha_{3}\left(1-\beta_{13}\right)\left(1-\beta_{23}\right)$ & $\alpha_{2}\left(1-\beta_{21}\right)\left[\alpha_{1}-\alpha_{3}\left(1-\beta_{31}\right)\right]+\alpha_{1} \alpha_{3}\left(1-\beta_{31}\right)$ \\
$Q_{3}(0,1,0)$ & $\left(\alpha_{1}+\alpha_{2}+\alpha_{3}\right)-\left(2 \alpha_{2}+\alpha_{1} \beta_{12}+\alpha_{3} \beta_{32}\right)-\alpha_{1} \alpha_{2} \alpha_{3}\left(1-\beta_{12}\right)\left(1-\beta_{32}\right)$ & $\alpha_{1}\left(1-\beta_{12}\right)\left[\alpha_{2}-\alpha_{3}\left(1-\beta_{32}\right)\right]+\alpha_{2} \alpha_{3}\left(1-\beta_{32}\right)$ \\
$Q_{4}(1,0,0)$ & $\left(\alpha_{1}+\alpha_{2}+\alpha_{3}\right)-\left(2 \alpha_{1}+\alpha_{2} \beta_{21}+\alpha_{3} \beta_{31}\right)-\alpha_{1} \alpha_{2} \alpha_{3}\left(1-\beta_{21}\right)\left(1-\beta_{31}\right)$ & $\alpha_{1}\left(1-\beta_{13}\right)\left[\alpha_{3}-\alpha_{2}\left(1-\beta_{23}\right)\right]+\alpha_{2} \alpha_{3}\left(1-\beta_{23}\right)$ \\
\hline
\end{tabular}

(2) Model analysis

The development of the systems will eventually stabilize, and the stable point represents for 
the development direction of the systems. Point $Q_{1}(0,0,0)$ is an unstable point, at which time none of the three subsystems will have a stable state. $Q_{2}(0,0,1), Q_{3}(0,1,0)$ and $Q_{4}(1,0,0)$ are the extreme points. At this time, each of the three subsystems reaches its maximum value by squeezing the rest of the systems. One subsystem will reach its limit and the remaining two subsystems will die out, reflecting the state of complete independence on the systems. Balance point $Q_{5}\left(x_{1}, x_{2}, x_{3}\right)$ corresponds to systems $S_{1}, S_{2}$ and $S_{3}$. There is a state of evolution. The evolution corresponds to an increase or decrease in the order of the systems. Analyzing the balance point, two situations of co-evolution can be obtained:

(1Partially competitive substitution, which corresponds to points $Q_{2}(0,0,1), Q_{3}(0,1,0), Q_{4}(1,0,0)$. When the output systems and support systems have strong impacts on the input systems $\left(\beta_{12}>1\right.$ and $\left.\beta_{13}>1\right)$, the negative growth of the input systems indicates that insufficient output and unreasonable support resources have led to the decline of the input systems; when the input systems and support systems have strong influences on the output systems $\left(\beta_{21}>1\right.$ and $\left.\beta_{23}>1\right)$, the negative growth of the output systems indicates that excessive or insufficient resource input and environmental support have caused the decline of the output systems; when the input systems and output systems have strong influences on the support systems $\left(\beta_{31}>1\right.$ and $\left.\beta_{32}>1\right)$, the negative growth of the support systems indicates that inappropriate input resources and insufficient output of technology achievements have led to the decline of the support systems.

21Partial competition coexists, which corresponds to points $Q_{5}\left(x_{10}, x_{20}, x_{30}\right)$. The influence of the competition among the input systems, output systems and support systems is not equal. There is competition and cooperation. If certain conditions are met, the three subsystems can develop together and move towards a stable structural state $Q_{5}\left(x_{10}, x_{20}, x_{30}\right)$ to synergy evolution.

\subsection{Co-evolution model parameters solutions of low-carbon technology innovation compound systems of new energy enterprises based on genetic algorithm}

Genetic Algorithm (GA), as a heuristic random search algorithm, which provides a new method for solving problems based on evolutionary thinking. The genetic algorithm starts from a group of points, which not only improves the efficiency of algorithm and running speed of the program, but also greatly reduces the possibility of falling into a local optimal solution. At the same time, without being restricted by constraints, it uses variable fitness information, only structure object functions and coding strings are needed, which reduces the import of other auxiliary information, so genetic algorithms can deal with almost any problems[42,43]. Therefore, this study chooses genetic algorithm to solve the co-evolution model parameters of low-carbon technology innovation compound systems of new energy enterprises. 
Genetic algorithm is a method of searching for the optimal solution by simulating the natural evolution process. Its main feature is to directly operate on structural objects. There is no restriction on derivation and function continuity, and it has inherent implicit parallelism and a better overall situation and optimization ability[44]. Specifically, it takes all individuals in a group as the objects, and uses randomization technology to guide the efficient search of coded parameter space, selection, crossover and variation constitute the operation of genetic algorithm, the operation calculation process is shown in Figure 1.

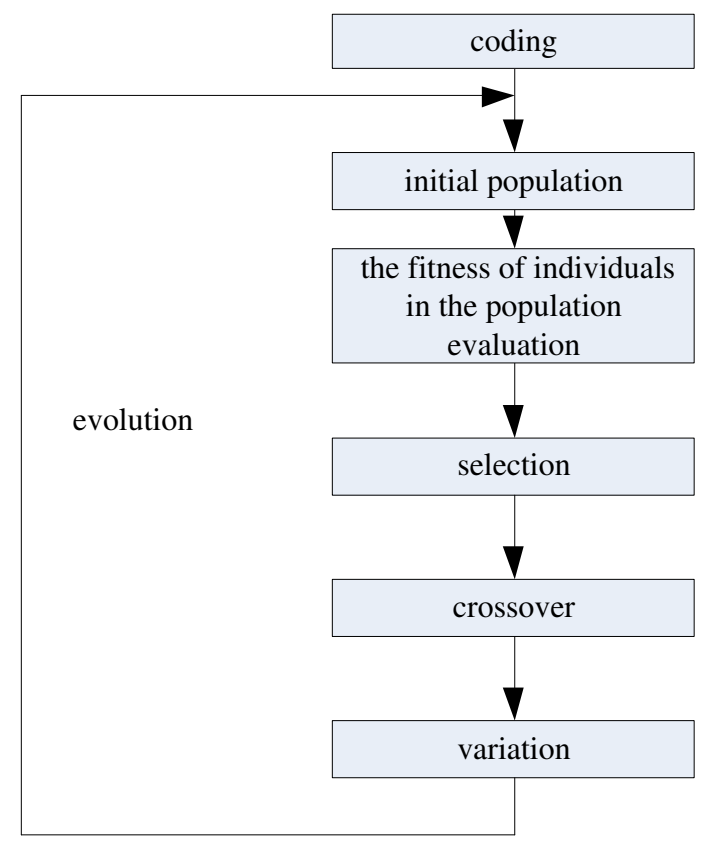

Figure 1 The calculation process of genetic algorithm

\section{Empirical analysis}

4.1 Order degree analysis of low-carbon technology innovation compound systems of new energy enterprises

According to the principles of systems coordination, comprehensiveness and operability, thi study considers the actual situation of new energy enterprises and the availability of index data, establishes the order index systems of low-carbon technology innovation compound systems [44-47], details are shown in Table 2.

Table 2 The order index systems of low-carbon technology innovation compound systems of new energy enterprises

\begin{tabular}{c|c|l}
\hline Measurement targets & Dominant reasons & \multicolumn{1}{c}{ Measurement indexes } \\
\hline low-carbon & & low-carbon technology R\&D capital investment \\
technology & capital resources input & as a proportion of operating income \\
\cline { 3 - 3 } innovation output & & low-carbon technology innovation financing \\
\hline
\end{tabular}




\begin{tabular}{|c|c|c|}
\hline \multirow[t]{5}{*}{ systems } & & change index \\
\hline & \multirow{2}{*}{ technical resource input } & $\begin{array}{l}\text { the proportion of low-carbon technology } \\
\text { introduction funds in operating income }\end{array}$ \\
\hline & & $\begin{array}{l}\text { low-carbon technology research and } \\
\text { development cost change index }\end{array}$ \\
\hline & \multirow{2}{*}{ human resources input } & $\begin{array}{l}\text { low-carbon technology innovation personnel } \\
\text { accounted for the proportion of total employees }\end{array}$ \\
\hline & & $\begin{array}{l}\text { low-carbon technology innovation personnel } \\
\text { technical training costs }\end{array}$ \\
\hline \multirow{5}{*}{$\begin{array}{c}\text { low-carbon } \\
\text { technology } \\
\text { innovation output } \\
\text { systems }\end{array}$} & \multirow{3}{*}{$\begin{array}{l}\text { low-carbon technology } \\
\text { innovation achievements }\end{array}$} & low-carbon technology patents granted \\
\hline & & low-carbon technology invention patents granted \\
\hline & & low-carbon technology sales growth rate \\
\hline & \multirow{2}{*}{$\begin{array}{l}\text { low-carbon technology } \\
\text { innovation application }\end{array}$} & low-carbon technology total asset growth rate \\
\hline & & low-carbon technology return on net assets \\
\hline \multirow{6}{*}{$\begin{array}{c}\text { low-carbon } \\
\text { technology } \\
\text { innovation support } \\
\text { systems }\end{array}$} & \multirow{2}{*}{$\begin{array}{l}\text { basic environment } \\
\text { support }\end{array}$} & $\begin{array}{l}\text { low-carbon technology innovation } \\
\text { comprehensive payment change index }\end{array}$ \\
\hline & & $\begin{array}{l}\text { low-carbon technology innovation equipment } \\
\text { continues to update the index }\end{array}$ \\
\hline & $\begin{array}{l}\text { cultural environment } \\
\text { support }\end{array}$ & $\begin{array}{l}\text { low-carbon technology culture promotion and } \\
\text { education expenses }\end{array}$ \\
\hline & $\begin{array}{c}\text { government environment } \\
\text { support } \\
\end{array}$ & $\begin{array}{l}\text { Low-carbon technology innovation policy } \\
\text { subsidy }\end{array}$ \\
\hline & \multirow{2}{*}{$\begin{array}{l}\text { market environment } \\
\text { support }\end{array}$} & $\begin{array}{l}\text { low-carbon technology innovation market } \\
\text { transaction rate }\end{array}$ \\
\hline & & $\begin{array}{l}\text { investment in low-carbon technology innovation } \\
\text { projects }\end{array}$ \\
\hline
\end{tabular}

This study selects 12 new energy enterprises of BYD Automobile Co., Ltd.(BYD), Sinovel Wind Power Technology (Group) Co., Ltd.(SWPT), Xinjiang Goldwind Technology Co., Ltd. (XGT), Sungrow Power Supply Co., Ltd.(SPS), JA Solar Photovoltaic Technology Co., Ltd. (JASPT), Xiangdian Group Co., Ltd.(XGC), ENN Group(ENN), China Datang Corporation(CDC), Zhongtong Bus Holding Co., Ltd. (ZBH), China Huaneng Group(CHG), Changzhou Yijing Photoelectric Technology Co., Ltd. (CYPT), Jiangsu Linyang New Energy Co., Ltd(JLNE). among the "Top 30 New Energy Enterprises" from 2010 to 2019 as research sample. The industry distributions are as follows: five new energy comprehensive groups, two solar energy, two wind 
energy, two automotive new energy power enterprises, and one biomass energy enterprise. In terms of the nature of the enterprise, there are two state-owned enterprises and ten private enterprises. The data of each indicator derive from the annual report of new energy enterprises and the GTA database. Using the relevant data of the sample enterprises and the calculation formula (2) and formula (3) of the order degree, the order degree of low-carbon technology innovation compound systems of new energy enterprises is obtained, as shown in Figure 2.

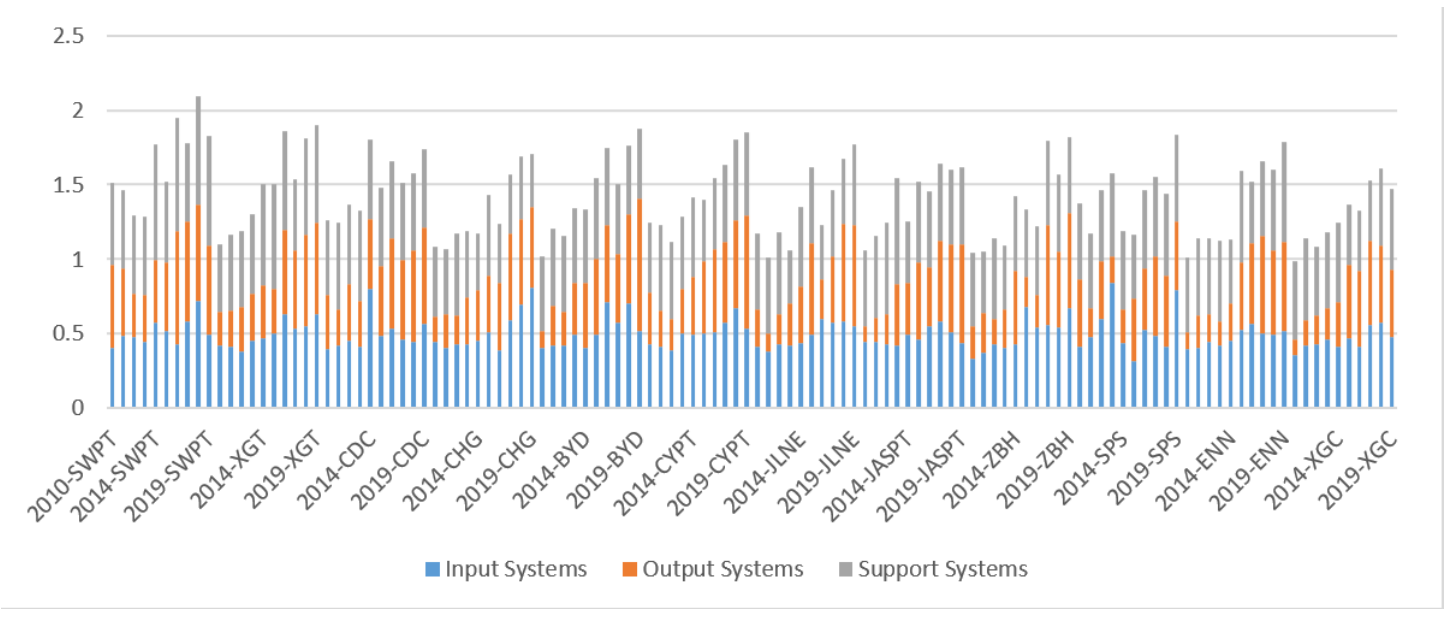

Figure 2 The order degree of low-carbon technology innovation compound systems of new energy enterprises

It can be seen from Figure 2 that from 2010 to 2019, the orderliness of low-carbon technology innovation compound systems of each new energy company is on the rise, and at the same time, the gaps in the level of low-carbon technology innovation among different new energy enterprises have been narrowing. Among them, the level of comprehensive new energy enterprises is slightly higher than other types of enterprises, and state-owned enterprises are slightly higher than private enterprises. Further this study uses the simple weighted average method to obtain the order level of the overall new energy enterprises, as shown in Figure 3. 


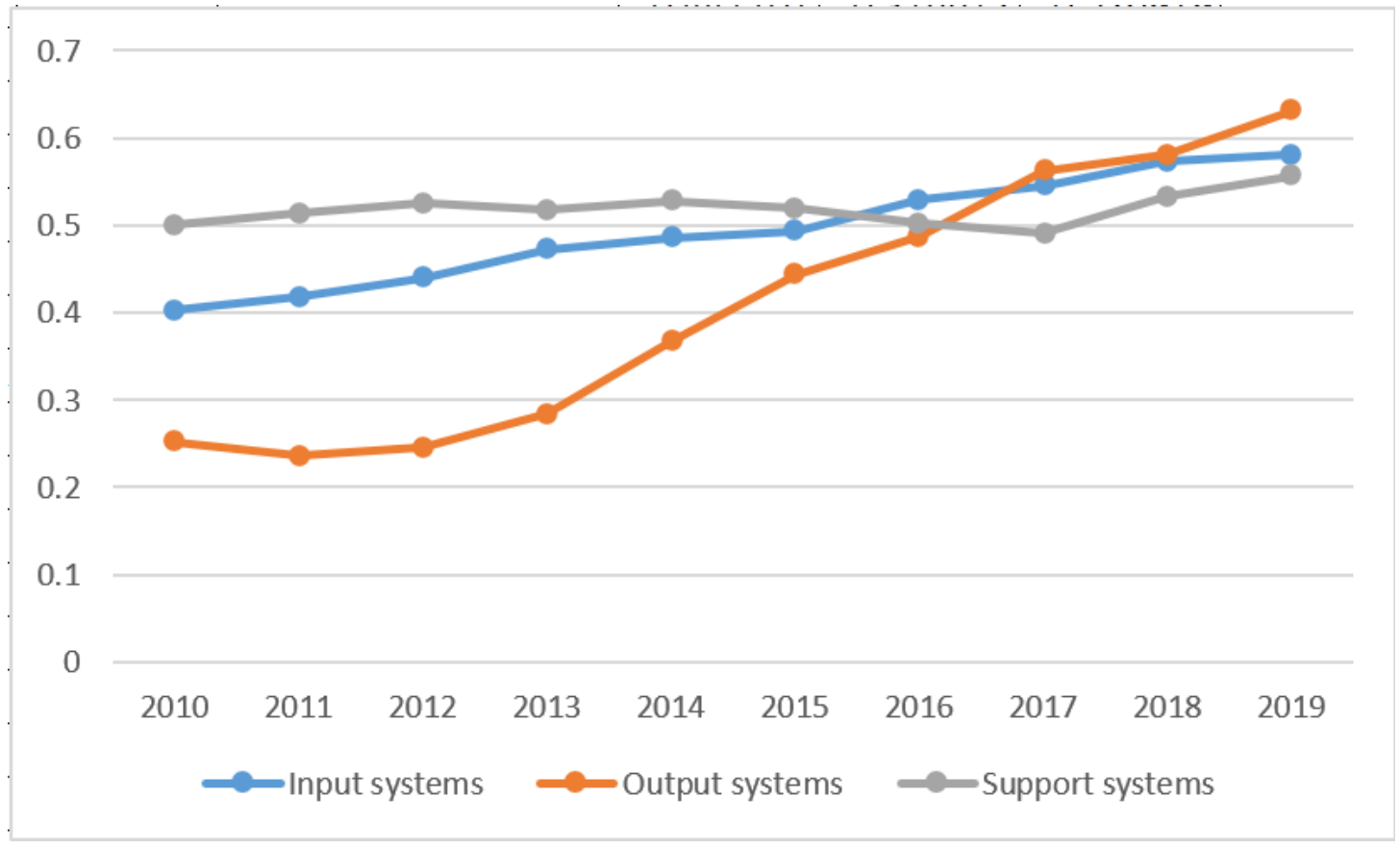

Figure 3 The overall order change trend of low-carbon technology innovation compound systems of new energy enterprises

It can be seen from Figure 3 that the three subsystems of input, output, and support have shown an upward trend from 2010 to 2019, indicating that the three have been fully developed in the past ten years. Especially since 2013, the output systems have experienced a strong upward trend. Since then, it has been rising for many years. The main reason is that during the "Eleventh Five-Year Plan" period, the country has vigorously developed the new energy industry. New energy enterprises have shown a leap-forward development and have continuously increased research and development. The scale of development and utilization of various renewable energy has increased significantly. Carbon technology is becoming more and more mature, and until the "Twelfth Five-Year Plan", the proportion of low-carbon technology innovation in the technological innovation structure of new energy enterprises continues to rise, which will inevitably lead to the development of the output systems with low levels in the early stage and rising levels in the later stage. In 2016, the input systems surpassed the support systems for the first time and had been showing an upward trend, indicating that the low-carbon technology innovation of new energy enterprises have successfully transformed from "external promotion" to "internal pull". Explore the reasons why Chinese new energy enterprises start late and low-carbon technology is not mature enough, large-scale research and application projects such as technology research and development mainly rely on national policy support. With the continuous progress of low-carbon technology and economic strength of new energy enterprises, in order to better achieve sustainable development, new energy enterprises will inevitably increase their inputs and 
investments to cause the input and investment systems to catch up with the support systems. At the same time, judging from the change in the slope of the curve, the support systems have maintained steady development over the past decade, and which have been the "pushing hand" for the steady low-carbon technology innovation of new energy enterprises.

\subsection{Analysis on the relationships of competition and cooperation of low-carbon technology innovation compound systems of new energy enterprises}

According to the above contents, the co-evolution model of low-carbon technology innovation compound systems of new energy enterprises based on genetic algorithm can be obtained:

$$
\left\{\begin{array}{l}
Z_{1}=\min \sum_{\mathrm{k}=1}^{12}\left[Y_{1}-\alpha_{1} \sum_{t=1}^{10} X_{1 t k}\left(1-\sum_{t=1}^{10} X_{t t k}-\beta_{12} \sum_{t=1}^{10} X_{2 t k}-\beta_{13} \sum_{t=1}^{10} X_{3 t k}\right)\right]^{2} \\
Z_{2}=\min \sum_{\mathrm{k}=1}^{12}\left[Y_{2}-\alpha_{2} \sum_{t=1}^{10} X_{2 t k}\left(1-\sum_{t=1}^{10} X_{2 t k}-\beta_{21} \sum_{t=1}^{10} X_{t t k}-\beta_{23} \sum_{t=1}^{10} X_{3 t k}\right)\right]^{2} \\
Z_{3}=\min \sum_{\mathrm{k}=1}^{12}\left[Y_{3}-\alpha_{3} \sum_{t=1}^{10} X_{3 t k}\left(1-\sum_{t=1}^{10} X_{3 t k}-\beta_{31} \sum_{t=1}^{10} X_{1 t k}-\beta_{32} \sum_{t=1}^{10} X_{2 t k}\right)\right]^{2}
\end{array}\right.
$$

Among them, the genetic algorithm has a crossover probability of 0.9 and a variation probability of 0.04 , the model parameters obtained are shown in Table 3.

Table 3 Calculation results of model parameters

\begin{tabular}{cccc}
\hline Subsystems & $\hat{\alpha}_{i}$ & $\hat{\beta}_{i j 1}$ & $\hat{\beta}_{i j 2}$ \\
\hline Input systems & 0.0714 & -1.0762 & 1.7331 \\
Output systems & 0.2102 & -0.3724 & 0.9120 \\
Support systems & 0.0713 & 0.5132 & -0.3255 \\
\hline
\end{tabular}

From the calculation results of $\hat{\alpha}_{2}>\hat{\alpha}_{1}>\hat{\alpha}_{3}>0$, it shows that the input, output, and support three subsystems of low-carbon technology innovation compound systems of new energy enterprises are all evolutionary systems. The output systems evolve the fastest, and the input systems and the support systems are almost the same.

It can be seen from $\hat{\beta}_{12}$ and $\hat{\beta}_{21}$ that the two subsystems of input and output in the low-carbon technology innovation compound systems of new energy enterprises are under win-win relationships. The reason is that the abundant and reasonable resource inputs of new energy enterprises meet the requirements of low-carbon technology innovation, and enable the widespread application of low-carbon technology innovation, thus revitalize the output systems and gain more market space. The input systems have cooperative effect on the output systems. At the same time, the more active the output systems of new energy enterprises is, the more rapid the accumulation of capital for new energy enterprises is, thereby it can improve the resource environment. At the same time, the market feedback of the output systems is conducive to the 
adjustment of the input structure of input systems, and which realizes the mutual promotion of input and output systems.

It can be seen from $\hat{\beta}_{13}$ and $\hat{\beta}_{31}$ that the two subsystems of input and support in the low-carbon technology innovation compound systems of new energy enterprises have a lose-lose relationships. The input systems hinder the input of the support systems, which in turn delay the input of the support systems. This is mainly due to the allocation of resources. The resources of the input systems and the support systems are similar, and resources are both exclusive and exclusive in usage and configuration. There are overlaps and redundancy. Improper allocation of low-carbon technology innovation resources for new energy enterprises will lead to resource conflicts and redundancy, that is, excessive improper usage of a certain resource into the systems or support systems will cause another systems to be formed. competition.

It can be seen from $\hat{\beta}_{23}$ and $\hat{\beta}_{32}$ that the output and support subsystems in the low-carbon technology innovation compound systems of new energy enterprises are mutually complementary. Mature output systems can bring about abundant resources and abundant capital for low-carbon technology innovation of new energy enterprises, and further strengthen the activity of the support systems. Therefore, the output systems have cooperative influences on the support systems. The existence of the support systems is in the long-term of stable and sustainable development of new energy enterprises, which has led to the fact that new energy enterprises do not use low-carbon technology innovation as the only means and paths. The systems have a competitive impact. The results take on competitive relationships.

Using the parameters found in Table 3, the values corresponding to the five equilibrium points of $\mathrm{Q}_{1}, \mathrm{Q}_{2}, \mathrm{Q}_{3}, \mathrm{Q}_{4}, \mathrm{Q}_{5}$ can be calculated, as shown in Table 4.

Table 4 Discrimination value table of equilibrium point stability

\begin{tabular}{cccc}
\hline Balance Points & $p$ & $q$ & $r$ \\
\hline$Q_{1}(0,0,0)$ & 0.3529 & 0.0011 & 0.0051 \\
$Q_{2}(0,0,1)$ & -0.1052 & 0.0001 & 0.0130 \\
$Q_{3}(0,1,0)$ & 0.0326 & -0.0029 & 0.0370 \\
$Q_{4}(1,0,0)$ & 0.2518 & -0.0007 & -0.0014 \\
$Q_{5}\left(x_{10}, x_{20}, x_{30}\right)$ & -0.8607 & -0.0011 & -0.1333 \\
\hline
\end{tabular}

According to the above analysis results, $\mathrm{Q}$ is a stable point where the input systems, output systems, and support systems are jointly developing towards a stable structural state. Its coordinates are $(3.1557,2.1130,0.0683)$, which represents for the current conditions of the input, output and support systems under the extreme values, that is, the continuous competition, evolution and coordination development exist among the three subsystems. Competition keeps the 
input, output and support systems alive and continues to evolve. Cooperation makes the input, output and support systems obtain sufficient development space. With the continuous improvement of low-carbon technology innovation level of new energy enterprises, new development vitality and impetus will be formed, and which make coordinated evolution to a higher level of stability.

\section{Conclusion}

From the perspective of sustainable development, low-carbon technology innovation is not only to solve the current energy problems, but also to realize the sustainable development of mankind, and to solve more environmental problems caused by energy and development. The new energy industry is a key industry in the world. Based on the perspective of sustainable development and synergetics theory, this study establishes low-carbon technology innovation compound systems of new energy enterprises, collaborative dynamic evolution model is composed of input, output and support systems. And further this study analyzes the balance points of the model using genetic algorithms and stability based on the statistical data of low-carbon technology innovation compound systems of 12 representative enterprises in the "Top 30 New Energy Enterprises" from 2010 to 2019, empirical research is conducted. The results show that: (1)The collaborative dynamic evolution model of low-carbon technology innovation compound systems of new energy enterprises can better reflect the dynamic co-evolution relationships of low-carbon technology innovation compound systems of new energy enterprises.(2)The order of low-carbon technology innovation compound systems of new energy enterprises shows that the order of low-carbon technology innovation compound systems of each new energy enterprise is rising. At the same time, the low-carbon technology innovation level gaps among different new energy enterprises have been narrowing. Among them, the level of comprehensive new energy enterprises is slightly higher than that of other types of enterprises, and the level of state-owned enterprises is slightly higher than that of private enterprises. From the perspective of the orderly level of low-carbon technology innovation of new energy enterprises, the three subsystems of input, output, and support have shown an upward trend during 2010-2019, indicating that the three have been fully developed in the past decade.(3)According to the model parameter estimation results, at present, the input, output and support three subsystems are all evolutionary systems, but there are differences in speed. The three subsystems have competition and cooperation relationships, the specific input systems and output systems are in win-win relationships, the input systems and the support systems are win-win relationships, and the output systems and the support systems are mutually complementary.(4)With the continuous development of low-carbon technology innovation compound systems of new energy enterprises, the three subsystems of 
input, output and support will be in a state of co-evolution. At the same time, the evolution of competition and cooperative development of the three will continue to improve low-carbon technology innovation level of new energy enterprises and make co-evolution be a higher level of stability.

The co-evolution model of low-carbon technology innovation compound systems of new energy enterprises proposed in this study provides new research perspectives for low-carbon technology innovation of new energy enterprises. The model can also be extended to co-evolution research of other compound systems. However, this study still has certain limitations and needs to be analyzed in future research. Firstly, it is necessary to further study and explore the calculation and determination of the balance points of the three-system compound systems; secondly, we can increase the research sample size and improve the universality of the research in order to better explain the dynamic co-evolution contents of low-carbon technology innovation compound systems of new energy enterprises.

\section{References}

1. Li S X, Lu X C (2011) The construction of national low-carbon innovation system: The road of the response to the climate change. Forum on Science and Technology in China. 12:15-20.

2. Lu X C, Liu L (2009) The construction of national low-carbon innovation system: The road of the response to the climate change. Forum on Science and Technology in China. 6:32-36.

3. Smith A, Voss J P, Grin J (2010) Innovation studies and sustainability transitions: The allure of the multi-level perspective and its challenges. Research Policy. 39(4):435-448.

4. Acot B A P (2016) Sectoral system of innovation and sources of technological change in machinery industry: An investigation on Turkish machinery industry. Procedia-Social and Behavioral Sciences.229:214-225.

5. Malerba F (2002) Sectoral systems of innovation and production. Research Policy. 31: 247-264.

6. Yi J C, Xu G Q, Zhao Y H (2011) Study on government-industry-research integration based on regional low-carbon innovation system. Energy Procedia. 5:2494-2498.

7. Luo J (2014) Research on the low-carbon technology innovation system of petroleum enterprises. Applied Mechanics \& Materials. 521:810-814.

8. Lundvall B-A (2010) National systems of innovation: Toward a theory of innovation and interactive learning. Anthem Press.

9. Weber M, Hemmelskamp J (2005) Towards environmental innovation systems. Springer.

10. Cooke P (2010) Regional innovation systems: Development opportunities from the "Green Turn". Technology Analysis \& Strategic Management. 22(7):831-844. 
11. Rogge K S, Joachim S (2018) Do policy mix characteristics matter for low-carbon innovation? A survey-based exploration of renewable power generation technologies in Germany. Research Policy. 162:491-504.

12. Kirchherr J, Urban F (2018) Technology transfer and cooperation for low carbon energy technology: Analysing 30 years of scholarship and proposing a research agenda. Energy Policy. 119(8):600-609.

13. Yin S, Li B Z (2018) A stochastic differential game of low carbon technology sharing in collaborative innovation system of superior enterprises and inferior enterprises under uncertain environment. Open Mathematics. 16(1):607-622.

14. Jiang Y G, Chun W D, Yang Y (2018) The effects of external relations network on low-carbon technology innovation: Based on the study of knowledge absorptive capacity. Sustainability. 10(2): 155-169.

15. Lai X D, Liu J X, Shi Q, Georgiev G, Wu G D (2018) Driving forces for low carbon technology innovation in the building industry: A critical review. Renewable \& Sustainable Energy Reviews. 74: 299-315.

16. Lai X D, Liu J, Georgiev G (2016) Low carbon technology integration innovation assessment index review based on rough set theory-An evidence from construction industry in China. Journal of Cleaner Production. 126:88-96.

17. Lema, Rasmus, Adrian (2016) Low-carbon innovation and technology transfer in latecomer countries: Insights from solar PV in the clean development mechanism. Technological forecasting and social change. 104:223-236.

18. Uyarra E, Shapira P, Harding A (2016) Low carbon innovation and enterprise growth in the UK: Challenges of a place-blind policy mix. Technological Forecasting \& Social Change. 103(11): 264-272.

19. Bai H, Han W X (2000) General theories about complex systems and their coordination. Operations Research and Management Science. 3:1-7.

20. Rosen R (1987) On complex systems. European Journal of Operational Research. 30(2): 129-134.

21. Omer A M (2007) Focus on low-carbon technologies: The positive solution. Renewable and Sustainable Energy Reviews. 4:1-27.

22. Wei W W, Chen X, Zhao S M (2012) Research on the evaluation model of Chinese enterprises' technological innovation system: From the perspective of complex system. Chinese Management Studies. 6(1):65-77.

23. Kao Y S, Nawata K, Huang C Y (2019) Systemic functions evaluation based technological 
innovation system for the sustainability of IoT in the manufacturing industry. Sustainability. 11: 2341-2376.

24. Bush R E, Bale C S E (2019) Energy planning tools for low carbon transitions: An example of a multicriteria spatial planning tool for district heating. Journal of Environmental Planning and Management. 62(12):2186-2209.

25. Linnenluecke M K, Han J L, Pan Z Y, Smith T (2019) How markets will drive the transition to a low carbon economy. Economic Modelling. 77: 42-54.

26. Wang M Y, Li Y M, Li M M, Shi W Q, Quan S P (2018) Will carbon tax affect the strategy and performance of low-carbon technology sharing between enterprises? Journal of Cleaner Production. 210: 724-737.

27. Yin H, Zhao J Y, Xi X, Zhang Y H (2019) Evolution of regional low-carbon innovation systems with sustainable development: An empirical study with big-data. Journal of Cleaner Production. 209(1):1545-1563.

28. Zhang H W (2019) Effect of low-carbon on enterprise competitiveness: A multiple mediation model. Applied Ecology and Environmental Research.17(4):8793-8803.

29. Xu J Z, Xu Y Y (2015) Low-carbon technology innovation diffusion under environmental regulation-Evolutionary game analysis based on prospect theory. Systems Engineering, 2:118-125.

30. Sun H (2012). Study on regional low-carbon technology innovation system abstract.Shandong Normal University.

31. Meng F S, Han B (2017) The impact of government environment regulation on low carbon technology innovation behavior of enterprises. Forecasting. 36(1):74-80.

32. Lyu X, Shi A N, Wang X (2020) Research on the impact of carbon emission trading system on low-carbon technology innovation. Carbon Management,11(2):183-193.

33. Boulogiorgou D, Ktenidis P (2019) TILOS local scale technology innovation enabling low carbon energy transition. Renewable Energy.146: 397-403.

34. Xu Y Y, Qi L Q (2016) Research on low carbon technology innovation diffusion of enterprise clusters based on evolutionary game theory and complex networks. Chinese Population, Resources and Environment. 26(8):16-24.

35. Shi D D (2015) Empirical study on influencing factors of low-carbon technology innovation of Chinese enterprises. Statistics \& Decision. (24):144-147.

36. Meng F S, Han B (2018) Research on dynamic mechanism of low carbon technology innovation of equipment manufacturing enterprises based on evolutionary game theory. Forecasting. 37(3):69-74. 
37. Jiang Q X, Zhou Z M, Wang Z L, Fu Q, Wang T (2018) Coordination and order risk assessment of water and land resource system based on periphery and synergetics theories. International Journal of Agricultural and Biological Engineering.11(3):146-153.

38. Hu X (2017) Study on designing service and management system for modern agricultural technology based on synergetics theory. Revista de la Facultad de Ingenieria. 32(11): 513-519.

39. Chen F, Chen S L, Cheng Y Y (2013) Research on the model of road traffic safety evaluation based on synergetics theory. Advanced Materials Research. 780:1028-1035.

40. Fan F, Sun C Z, Wang X N (2013) Social, economic and resource environment composite system of co-evolution-Case of Dalian. Systems Engineering Theory \& Practice. 33(2):413-419.

41. Zao S Q, Tang S F (2019). Influence indicator system for equipment utilization efficiency of active distribution network and its value calculation method. Electric Power Automation Equipment. 39(3):143-148.

42. Bradford E, Schweidtmann A M, Lapkin A (2018) Efficient multiobjective optimization employing Gaussian processes, spectral sampling and a genetic algorithm. Journal of Global Optimization. 71(2):1-33.

43. Ji G L (2004) Survey On Genetic Algorithm. Computer Applications and Software. (2):69-73.

44. Pettifor H, Wilson C, Mccollum D, Edelenbosch O Y (2018) Modelling social influence and cultural variation in global low-carbon vehicle transitions. Global Environmental Change. 47:76-87.

45. Yan Z M, Du K R, Yang Z M, Deng M (2017) Convergence or divergence? Understanding the global development trend of low-carbon technologies. Energy Policy. 109:499-509.

46. Polzin F (2017) Mobilizing private finance for low-carbon innovation-A systematic review of barriers and solutions. Renewable \& Sustainable Energy Reviews. 77:525-535.

47. Martina S, Sabine H, Willi H, Daniel H, Michaela L, Iris K, Sylvia M (2018) Facilitating low-carbon living? A comparison of intervention measures in different community-based initiatives. Sustainability.10(4):1047-1070. 


\section{Declarations}

\section{Ethics approval and consent to participate}

Not applicable.

\section{Consent for publication}

Not applicable.

\section{Availability of supporting data}

All data used in this study are from the annual report of new energy enterprises and the GTA database.

\section{Competing interests}

All authors declare that they have no competing interests.

\section{Funding}

This research was funded by the National Social Science Fund (Grant No.17CGL020);

Natural Science Foundation of Heilongjiang Province (Grant No.LH2019G005).

2019 Science Research Fund of Department of Education of Liaoning Province (Grant No. JQW201915402) .

\section{Authors' contributions}

$\mathrm{Xu}$ Yang and Qiang Liu provided the conceptual framework and the theoretical considerations. Deming Zhang collected and analyzed the patient data regarding the hematological disease and the transplant. Yu Guo was mainly responsible for the empirical research, and was a major contributor in writing the manuscript. All authors read and approved the final manuscript.

\section{Acknowledgements}

Not applicable. 
Figures

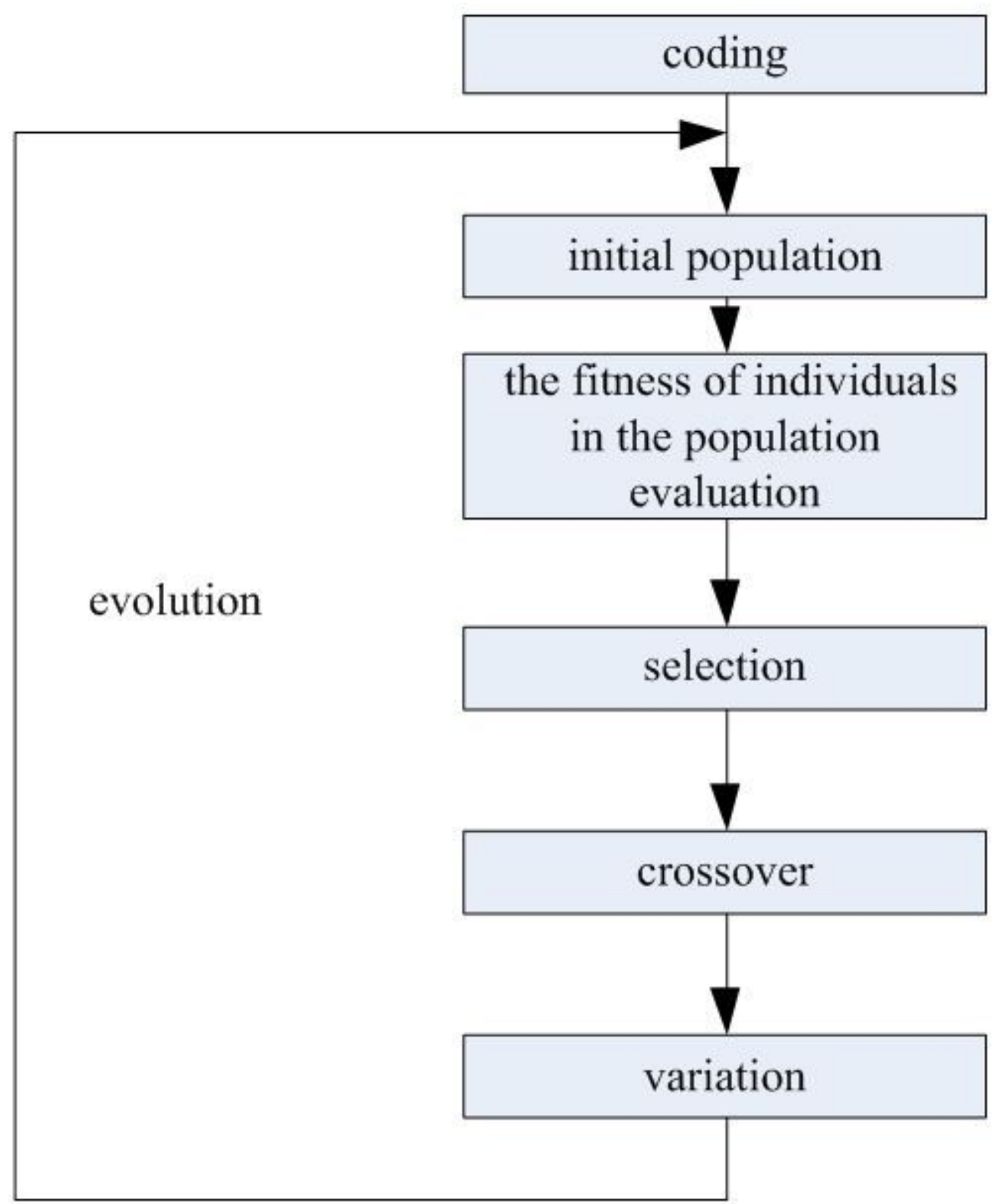

Figure 1

The calculation process of genetic algorithm 

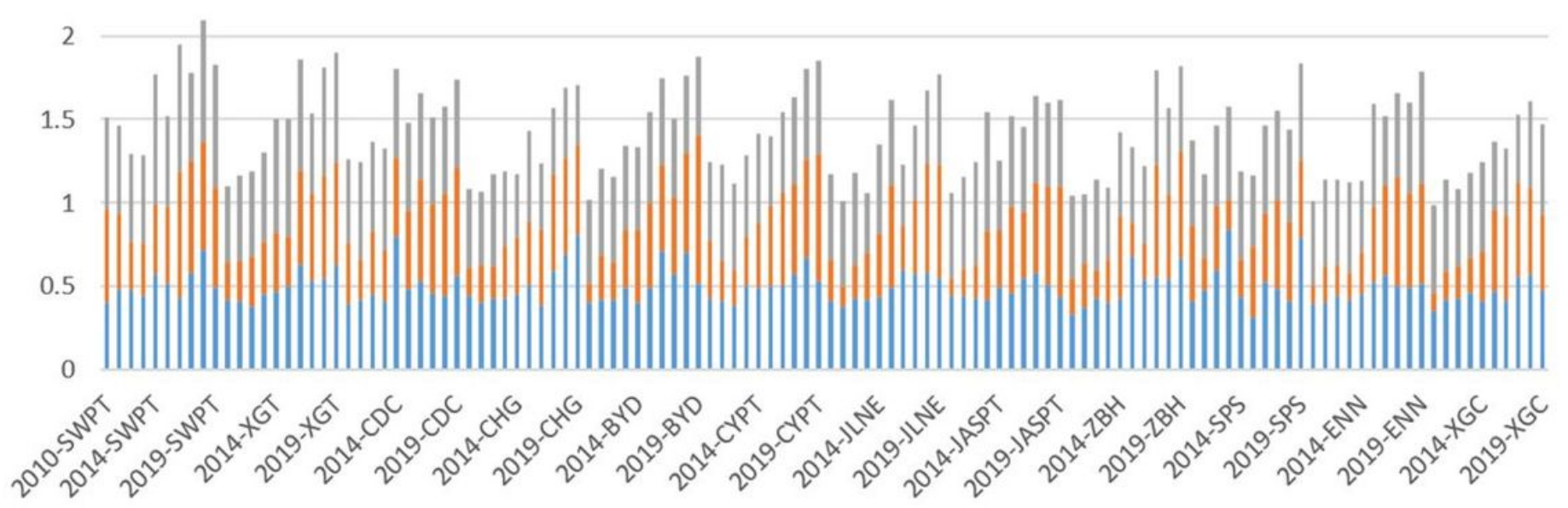

EInput Systems a Output Systems $\quad$ Support Systems

\section{Figure 2}

The order degree of low-carbon technology innovation compound systems of new energy enterprises

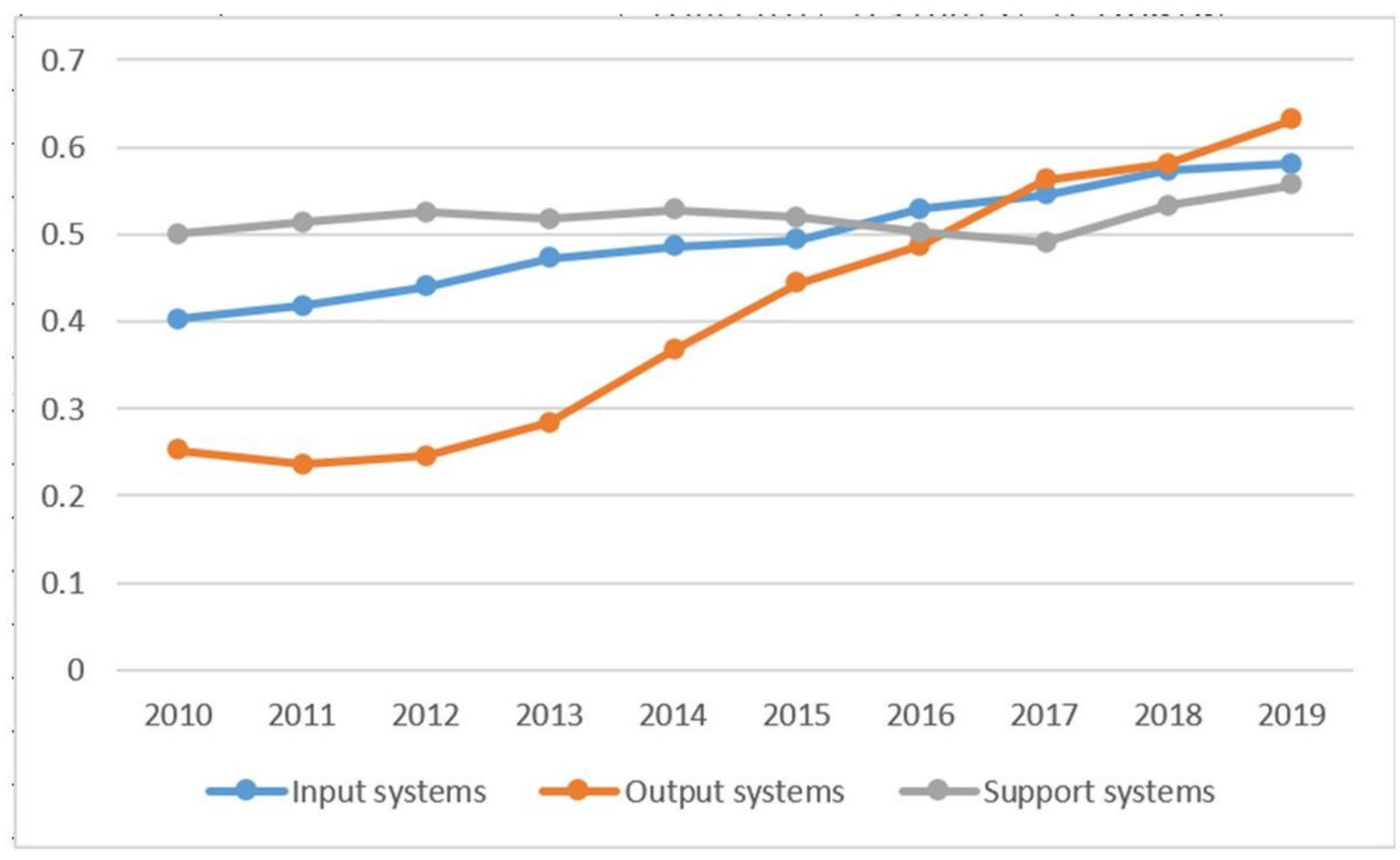

\section{Figure 3}

The overall order change trend of low-carbon technology innovation compound systems of new energy enterprises 